\title{
Computational Modeling of Fracture Toughness of Al-Si and Al-Zn-Mg-Cu Alloys with Detected Porosity
}

\author{
Jarosław Piekło, Aldona Garbacz-Klempka, Robert Żuczek, and Marcin Małysza
}

(Submitted August 28, 2018; in revised form January 2, 2019; published online February 19, 2019)

\begin{abstract}
This article presents the results of an experimental and numerical analysis of the fracture resistance of cast aluminum alloys subjected to variable loads over time based on the fracture mechanics method. The subjects of the analysis were the $\mathrm{AlSi} 9$ and $\mathrm{AlZn6MgCu}$ alloys (usually used for plastic processing) in which the presence of porosities in the form of separate or dispersed voids was revealed experimentally. The material for the experimental procedures was obtained directly from a casting or from casting samples. Depending on the type of the defect detected, different numerical models were proposed. The results of the numerical calculations were verified experimentally. Static tensile tests, fatigue low-cycle tests, fracture mechanics tests, fatigue crack propagation tests, a microscopic examination of the sample fracture area, and an x-ray tomographic analysis were all performed. A correlation of the results between the numerical analysis and the experimental work has been found. On the basis of the proposed calculation models, the fatigue life of castings of the analyzed alloys can be predicted in the case of concentrated and dispersed defects.
\end{abstract}

Keywords aluminum alloys, casting defects, FEM, fracture mechanics, material fatigue, numerical calculation

\section{Introduction}

When defects are detected in the casting part, three possible paths can mainly be taken:

- defective casting - scrap,

- repair,

- allow the casting to be exploited despite the detected irregularities (based on the work conditions).

A casting qualified as a scrap is associated with economic losses and entails a series of actions aimed at eliminating the causes or consequences of the defect. The priority action is to determine the causes of the defect and its elimination. This applies in particular to the mass production of low-weight castings. In some cases, repair is a good practice, especially when the price of a single cast is relatively high and the size of the series is small. In the final case (for example, releasing the casting for exploitation), the need to rationalize such a procedure is most visible. However, in the case of the repair decision, it seems important to determine the impact of the "unresolved" defect in the casting (including its durability) and understand the exploitation conditions of the casting.

The solution to the problem outlined above should be based on the theory of elasticity and plasticity, fracture mechanics,

Jarosław Piekło and Aldona Garbacz-Klempka, Faculty of Foundry Engineering, AGH University of Science and Technology, 23 Reymonta St., 30-059 Kraków, Poland; Robert Żuczek and Marcin Małysza, Foundry Research Institute, 73 Zakopiańska St., 30-418 Kraków, Poland. Contact e-mail: agarbacz@agh.edu.pl.

and issues related to material fatigue (adequately determined by the specific properties of the materials obtained by the casting methods). The numerical methods seem to be particularly useful in solving the given problem; these are the only ways to correctly determine the field values in the case of time-varying boundary conditions and nonlinear material characteristics.

The authors propose two different FEM calculation models to consider the defects in concentrated porosity or dispersed form.

\section{Research Methodology}

The research work was conducted for two aluminum alloys: AlSi9 (EN AC-44400) and AlZn6MgCu (EN AW-7010) in the as-cast state. The alloys were subjected to the T6 heat treatment procedure. The static tensile test, fatigue test, determining the critical stress intensity factor, and the Paris test are aimed at determining the relationship between the crack growth and the number of cycles. The test was carried out on an MTS 810 mechanical testing machine. The measurements of the sample elongation and gap dimensions were taken using MTS extensometers. The static tensile test was controlled by the strain rate, while the fatigue tests were controlled by the changes of force value. The measurement of the crack length and the duration of the process were recorded by a video camera. The number of cycles and the test time were controlled by the MTS machine software; this was based on the analysis of images from the computed tomography using ImageJ software. The analysis was performed to determine the areas of reduced density as related to the material of the matrix. The number of cross sections from the computed tomography image allows us to obtain a volumetric proportion of the microporosity in the analyzed casting sample unit. The image analysis of the computed tomography scans was performed in the Nanotom equipment. 


\section{Description of Porosity in Al-Si Alloys}

Castings made of aluminum alloys usually contain various types of structural discontinuities, which have a significant impact on their strength and fatigue properties. The structural discontinuities may be areas that are not properly filled with metal or include non-metallic inclusions that reduce the mechanical properties of the castings. The liquid aluminum is prone to hydrogen adsorption and oxidation; thus, the inevitable presence of gas porosity and oxide inclusions in aluminum castings is possible. If the casting is not properly fed, then the fatigue strength may be additionally reduced by the presence of shrinkage porosity. It has been confirmed by numerous fractography studies that gas porosity is usually circular in shape, while shrinkage porosity forms in irregular three-dimensional voids (Ref 1 ). Both types of porosity may occur together with aluminum oxide films. The structural discontinuities of the void type caused by the occurrence of porosity may have different sizes. It is possible to distinguish the microporosity when the diameters of the cavities do not exceed $100 \mu \mathrm{m}$ as well as the porosity when the diameters of the voids are greater than $100 \mu \mathrm{m}$ (Ref 2). Porosity and microporosity together greatly reduce the fatigue properties and strength of an alloy, while the occurrence of microporosity alone significantly decreases the fatigue strength within a range of a large number of cycles. The effect of microporosity on fatigue strength should be considered as related to the characteristics of the alloy microstructure, because the location of the microcrack initiation site depends on the mutual dimension relationship and distance between the voids and the microstructure phases. In the case of AlSi alloys, there is a view that the plastic properties of the alloy (like fatigue toughness) are similar depending on the distance between the secondary dendrite arms (SDAS) and the size of the silicon eutectic precipitates (Ref 3 ). According to research carried out by Wang (Ref 4) for the A356 alloy in the case of a coarse structure (SDAS $>60 \mu \mathrm{m}$ ), the fatigue process is most affected by the distances between the arms of the secondorder dendrites. In the case where the microstructure is fine (SDAS $<40 \mu \mathrm{m}$ ), the process is controlled by the size of the dendrite grains. Thus, the critical dimension of the void (which determines the smallest dimension above which microcracking can be initiated) depends on the size of the microstructure components. When solidification takes place slowly in sand molds for example, the critical dimension of the defect should be greater than the distance between the dendrite arms. For castings solidifying during pressure or gravity die casting, the defect may initiate a crack when it is larger than the grain size. The interaction of microstructure and porosity with fatigue strength changes as the number of load cycles increases. In castings made of the A1Si7 alloy, a reduction in the distance between the branches of dendrites (from 50 to $28 \mu \mathrm{m}$ ) and an increase in the porosity fraction (from 0.07 to $0.4 \%$ ) gives a total effect in the form of increased fatigue strength within the range below $1 \times 10^{5}$ cycles; for comparison, if the number of cycles is greater than $2 \times 10^{6}$, a loss of strength is observed (Ref 5). This can be justified by the fact that, during the low-cycle fatigue (in contrast to high-cycle fatigue), plastic deformation occurs, and as mentioned above, the plastic properties of the alloy depend strongly on the distance between the dendrite arms (as mentioned above). Above the critical dimension of the void, the size of the defect strongly affects the fatigue strength of the alloy. The reason for the crack initiation in the range of the small number of cycles is the presence of a defect constituting a strong stress concentrator. The crack growth velocity is controlled by the cyclic changes of the stress intensity factor, which depends on the amplitude of the stress on the defect position and cross-sectional surfaces (inside or on the surface of the sample). The fatigue strength of light foundry alloys within the range of a large number of cycles with defects within a range of $50-100 \mu \mathrm{m}$ depends on the surface area of the largest defect and crack propagation velocity in a given alloy. The Wohler curves for the foundry Al alloys tested at ambient temperature are characterized by the fact that the fatigue limit cannot be determined on their basis, even if the number of cycles exceeds $10^{8}$ or $10^{9}$ (Ref 6). Studies conducted on eutectic Al-Si alloys show that the cracking mechanisms of castings and processed alloys (plastic processing, forging) differ from each other (Ref 7). According to Murakami (Ref 8), the fracture initiates in the Al matrix in cracked alloys and increases to the critical value according to the II fracture model (which is longitudinal shear). The cracks are arranged at an angle of $45^{\circ}$ to the surface of the test sample. Usually, no other types of cracks can be observed. The crack develops rapidly, and the fatigue initiation phase (the lifetime of the structure) has the greatest impact on the crack initiation phase. Cracks of this nature arise before the possible separation of the $\mathrm{Si}$ phases and the matrix. $\mathrm{Si}$ precipitation may stop the development of a crack to arise. If there is insufficient Si precipitation, a fracture in the Al matrix can easily develop. Casting alloys do not show a clear limit of fatigue, even within a range of more than $10^{8}$ cycles. If microporosity occurs in the alloy, the fracture initiates in the Al phase next to the defect location and develops according to the II method of fracture. The cracking mechanism within the range of a small number of cycles is the same as for highcycle fatigue - a similar type of fracture area is observed. This fact is of particular importance in predicting the fatigue life of the casting part that was exposed to stress within the range of high- and low-cycle fatigue. The summarized damage influences the impact on both stages of crack development (initiation and propagation). In the alloy after plastic working, the initiation and cracking mechanisms are substantially different for the cast alloy. The location of the initiation of the crack is the precipitation of $\mathrm{Si}$ or the intermetallic surface of the Al matrix and the precipitation of Si. The cracks initiate relatively early within the $\mathrm{Si}$ precipitates, and cracking develops according to the first method (i.e., the opening of the fracture surface). This type of mechanism occurs when the number of cycles needed for destruction is fewer than $10^{8}$. Above this number of cycles, the mechanism of destruction is similar to the cast alloys (i.e., through the shear and initiation of the crack in the Al phase). In the plastic-processed alloys, fatigue strength can be more accurately determined within a range of $10^{7}$ cycles; this limit becomes even more noticeable when microporosity is present in the alloy. The cracking mechanism for a low number of cycles is the same as for high-cycle fatigue. The conducted research confirms the negative effect of the coarse structure and porosity on the fatigue strength of $\mathrm{Al}$ alloys; however, the quantitative methods developed so far do not fully allow us to take into account the influence of the shape, type, and distribution of the defects. 


\section{Description of Porosity in Al-Zn-Mg-Cu Alloys}

In the case of aluminum alloys containing zinc (like the $\mathrm{AlZn} 6 \mathrm{MgCu}$ alloy), the construction of high-strength castings still remain at the stage of initial testing and are described in Ref 9-14. The 7XXX series alloys usually used for plastic processing are characterized by high strength (over $500 \mathrm{MPa}$ ) and good plasticity (reaching as high as $20 \%$ ). The lack of plastic working (forging, rolling) eliminates one of the strengthening mechanisms (which is mechanical hardening). In this case, the microstructure of the alloy is determined by the solidification and heat treatment process. The high strength of the 7XXX series alloys results from the mechanism of precipitation of the intermetallic phase particles within the saturated solid solution $\alpha \mathrm{Al}$ (precipitation strengthening). However, the dynamics of the separation as well as the formation of phases such as $\eta\left(\mathrm{AlZn}_{2}\right), \mathrm{T}\left(\mathrm{Al}_{6} \mathrm{CuMg}_{4}\right)$, and $\mathrm{S}$ $\left(\mathrm{Al}_{2} \mathrm{CuMg}\right)$, which significantly affect the properties of the alloy, depends on its chemical composition and cooling rate (Ref 15). To increase the strength of the alloy, a high content of zinc is preferred, as it causes a reduction in the number of Tphase precipitates; however, an excessive amount makes it difficult to obtain fair plasticity. The casting part usually has a variable wall thickness, where the solidification rates differ significantly. This problem is particularly important in the case of the analyzed alloys because of the wide solidification range (above $150{ }^{\circ} \mathrm{C}$ ). This phenomenon is conducive to the formation of shrinkage porosity and shrinkage gas microporosity. The appropriate balance of three important elements $(\mathrm{Zn}, \mathrm{Mg}$, and $\mathrm{Cu}$ ), the reduction of impurities such as $\mathrm{Fe}$ and $\mathrm{Si}$, and a suitably selected heat treatment process all have an impact on the optimal structure and properties of the alloy. Depending on the type of porosity present in the cast and its percentage, the following calculation models are proposed as well as examples of their use (supported by experimental research).

\section{Laboratory Trials}

The experimental laboratory trials included static tensile tests, low-fatigue cycle tests, fracture mechanics tests, fatigue crack propagation tests, the so-called Paris test, a microscopic examination of the sample fracture area, and an x-ray tomographic analysis. The selection of the tests carried out depends on the types of defects found in analyzed alloys.

\subsection{Analysis of AlSig Alloy}

The analysis of the AlSi9 alloy (whose chemical composition is presented in Table 1) was conducted to determine the strength properties necessary for defining the cracking resistance of the alloy in a constant and time-varying stress field in the case of a concentrated internal defect. Strength tests were

Table 1 Chemical composition of AISi9 alloy (wt.\%)

\begin{tabular}{lccccccc}
\hline \multicolumn{7}{c}{ Concentration, wt.\% } \\
\hline Si & Cu & Fe & Mn & Ti & Zn & Mg & Al \\
\hline 9.2 & 0.10 & 0.30 & 0.45 & 0.14 & 0.15 & 0.08 & Bal. \\
\hline
\end{tabular}

carried out on samples with a diameter of $8 \mathrm{~mm}$ obtained from a casting that was previously subjected to heat treatment. The alloy was subjected to the T6 heat treatment procedure with solutioning at a temperature of $540{ }^{\circ} \mathrm{C}$ and held up for $6 \mathrm{~h}$ (for acquiring a homogeneous solid solution) and cooling in water. Aging was conducted at $160{ }^{\circ} \mathrm{C}$ for $10 \mathrm{~h}$. The static tensile test was carried out under the ISO 6892-1 standard at the ambient temperature. The deformation velocity was $e=0.00025 \mathrm{~s}^{-1}$.

The conducted trials were taken to determine the critical value of stress intensity coefficient $K_{\mathrm{IC}}$. The trials were carried out on "compact"-type samples (based on the PN-EN ISO 12737:2011 standard) with a thickness $(B)$ of $22 \mathrm{~mm}$. The tests of the fatigue crack growth rate at constant sinusoidal load amplitude $\Delta P=6.0 \mathrm{MPa}$ and cycle asymmetry $R=0.1$ were carried out on "compact"-type samples with a thickness $(B)$ of $15 \mathrm{~mm}$ and a $W / B$ ratio of 4 (where $W$ is the perpendicular dimension in the direction of the crack propagation).

The increases in the crack lengths were measured on samples whose surfaces were first polished and then applied with a millimeter scale on both sides. The crack growth was determined by filming this phenomenon along with the registration of the number of fatigue cycles and the duration of the test.

The recorded image was subjected to computer image analysis, which resulted in the relationship between crack growth and the number of cycles. The research was based on the ISO 12108:2012 standard. Based on the above relationships, charts showing crack growth rate $\mathrm{d} a / \mathrm{d} N$ as a function of the changes in stress intensity factor $\Delta K$ were prepared, and the appropriate $\mathrm{C}$ and $\mathrm{m}$ constants were determined (Table 2).

\subsection{Analysis of AlZn6MgCu Alloy}

The tomography research work conducted on the samples obtained from the $\mathrm{AlZn} 6 \mathrm{MgCu}$ alloy plate casting with the chemical composition shown in Table 3 and mechanical properties listed in Table 4 revealed the presence of both microporosity and (in some areas) macroporosity. In order to better visualize the spread of the test, the results of the fatigue tests are presented on the curves where stress amplitude $\sigma_{\mathrm{a}}$ is given on the axis of the ordinates and the number of $\mathrm{N}$ cycles is provided on the abscissa axis (Fig. 1).

The fracture surface of the samples after the fatigue tests in a low number of cycles was also subjected to microscopic observation in order to detect possible non-metallic inclusions, porosity, or oxide films and compared them to samples where such discontinuities in the structure were not detected in the means of reduced fatigue strength. Computational analyses were carried out in the case of revealing defects whose dimensions were so large that the influence of the microstructure on crack initiation could be neglected and clearly stated that the defects are the initiators of the cracks. Based on the analysis of sample photographs from the tomographic examinations, the qualitative and quantitative distribution of microporosity was estimated. The tests were carried out with the use of an x-ray computer tomographer by GE (type Vtomex) using exposure parameters of $200 \mathrm{kV}$ and $250 \mu \mathrm{A}$ and a size of the voxel of $9 \mu \mathrm{m} / \mathrm{vox}$. The representative assumed areas of the analysis are located next to the sample bend site at a normative width of the analyzed area of $8 \mathrm{~mm}$. Examples of photographs revealing the occurrence of micropores that were obtained on the basis of the tomographic examinations in the form of cross sections perpendicular to the axis of the sample are shown in 
Table 2 Results of tensile tests and fracture resistance of AISi9 alloy

Constant in Paris equation

\begin{tabular}{lccccc}
${ } }$ & Tensile strength UTS, MPa & UTS/YS & Fracture toughness $\boldsymbol{K}_{\mathrm{IC}}, \mathbf{M P a}^{\mathbf{0 . 5}}$ & $\boldsymbol{C}$ & $\boldsymbol{m}$ \\
\hline 257 & 274 & 1.066 & 16.6 & $4.56 \times 10^{-16}$ & 11.41 \\
\hline
\end{tabular}

Table 3 Chemical composition of AlZn6MgCu alloy (wt.\%)

\begin{tabular}{llllllllll}
\hline \multicolumn{10}{c}{ Concentration, wt.\% } \\
\hline $\mathbf{Z n}$ & $\mathbf{M g}$ & $\mathbf{F e}$ & $\mathbf{C u}$ & $\mathbf{M n}$ & $\mathbf{Z r}$ & $\mathbf{T i}$ & $\mathbf{B e}$ & $\mathbf{S i}$ & $\mathbf{A l}$ \\
\hline 5.8 & 1.98 & 0.08 & 1.53 & 0.10 & 0.13 & 0.10 & 0.14 & 0.06 & Bal. \\
\hline
\end{tabular}

Table 4 Results of $\mathrm{AIZn6MgCu}$ alloy static tensile test on samples cut from plate casting

\begin{tabular}{lccc}
\hline UTS, MPa & YS, MPa & $\boldsymbol{A}, \%$ & $\boldsymbol{E}, \mathbf{M P a}$ \\
\hline 442 & 417 & 1.21 & 73,630 \\
\hline
\end{tabular}

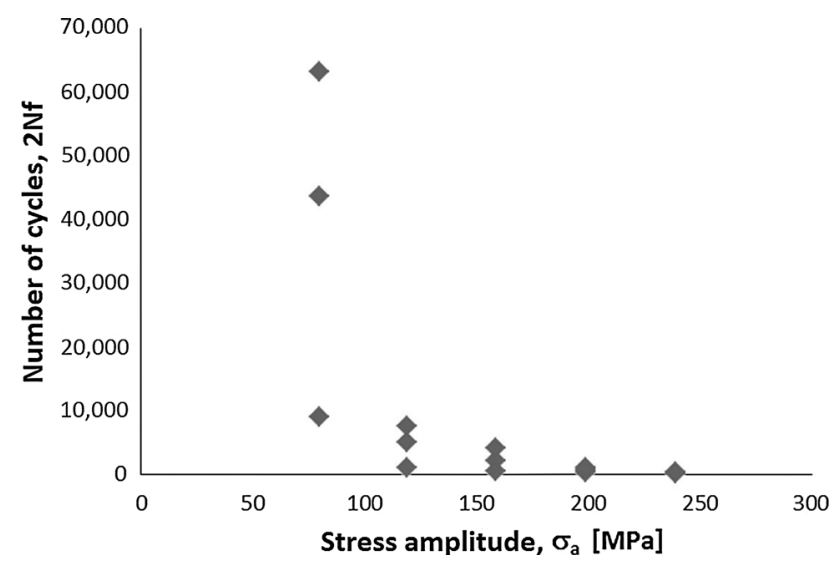

Fig. 1 Relationship between stress amplitude $\sigma_{\mathrm{a}}$ and number of cycles $N$ needed for destruction of samples obtained from $\mathrm{AlZn} 6 \mathrm{MgCu}$ alloy casting plate

Fig. 2. Based on these, the porosity participation in the entire representative volume of the sample was determined.

An image analysis of the sample cross sections obtained in the computed tomography was carried out using ImageJ software. Using the modules of noise and interference reduction as well as the appropriate filters, the program was calibrated to allow us to extrapolate the areas with internal discontinuities. The automatic image analysis was carried out on a selected range of sample cross sections, allowing for a qualitative and quantitative estimation of the discontinuities of the structure along with their location in the volume space. In the conducted analysis, the percentage share of the microporosity represented by the shaded areas as related to the matrix and other elements of the structure was obtained.

The results of the tests are given in Table 5. The results show the relationship between the number of cycles needed for destruction and the microporosity detected by x-ray tomography for five values of the stress amplitude. The study reveals the clear effect of increases in the content of porosity on the reduction of the fatigue life of the alloy.

\section{Computational Models of Defects}

Depending on the size and shape of the defect, different calculation models were proposed that can be used to determine the stress state in the area of the defect as well as the $K_{\mathrm{I}}$ value in order to predict the durability of castings with discontinuities. In the computational models, the results of the conducted experimental tests were used.

\subsection{Defect Concentrated in Area of Constant Stress}

In the case when the length of the defect measured in a direction perpendicular to the force vector is greater than $1.0 \mathrm{~mm}$ (Ref 16), the methods of fracture mechanics can be used to predict its impact on the possible damage in the casting. The defect is then considered to be a gap, with the vertex as a strong concentration of the stress that can become a crack initiation area. Analytically or numerically calculated stress intensity factor $K_{\mathrm{I}}$ (depending on the length of gap $a$, the geometry parameter determined by " $Y$," and nominal stress $\left.\sigma_{\text {nom }}\right)$ is the value on the basis of which it is possible to estimate the current state of the material resistance to cracking by comparing it with the critical value-experimentally determined material constant $K_{\mathrm{IC}}$.

$K_{\mathrm{I}}=\sigma_{\text {nom }} \sqrt{\pi a} \cdot Y$

The shape of small defects, including foundry defects differs from the classical model of the gap considered by the fracture mechanics. Therefore, the so-called surface parameter " $A$ " has been implemented. If the discontinuity has a regular shape, then the geometric parameter is directly equal to the surface of the defect (Ref 8):

$K_{\mathrm{I}}=\alpha \cdot \sigma_{\mathrm{nom}} \sqrt{\pi \sqrt{A}}$

If the defect is located inside the casting wall, the coefficient takes a value $\alpha=0.5$ if is located on the surface than $\alpha=0.6$. In the case of an irregular defect shape, the geometric parameter 

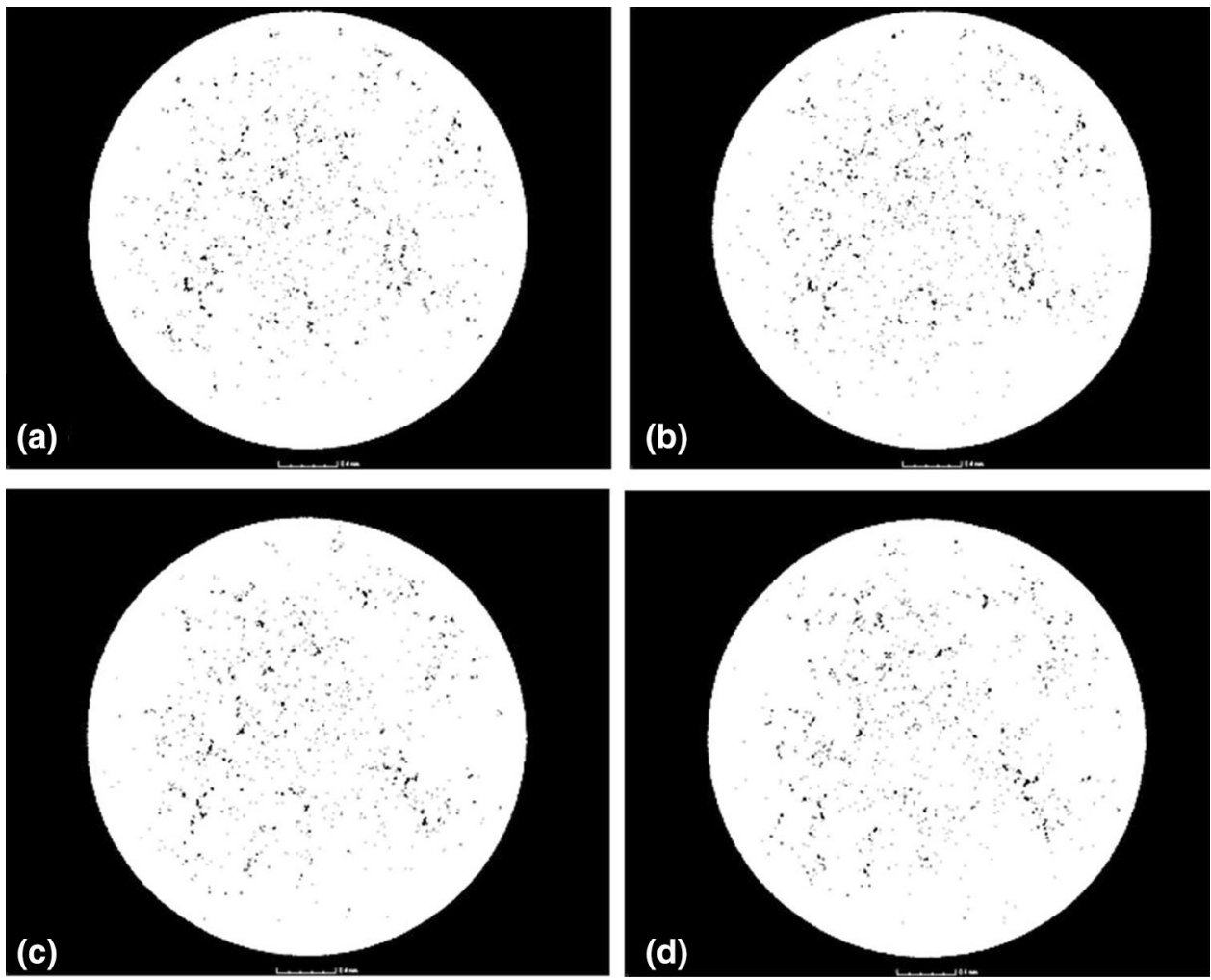

Fig. 2 Percentage of microporosity in four different cross sections of representative area: (a) and (d) cross sections limiting area; (b) and (c) cross sections within area. Number of cycles for destruction $-43,566$; stress amplitude $-79.6 \mathrm{MPa}$ (1-mm scale)

Table 5 Microporosity determined by x-ray tomography compared with number of cycles needed for destruction of sample in cases of different stress amplitudes used in fatigue tests

\begin{tabular}{lcc}
\hline $\begin{array}{l}\text { Stress } \\
\text { amplitude, MPa }\end{array}$ & $\begin{array}{c}\text { Number of cycles leading to } \\
\text { destruction }\end{array}$ & $\begin{array}{c}\text { Microporosity, } \\
\%\end{array}$ \\
\hline 79.6 & 43,566 & 0.157 \\
& 63,037 & 0.092 \\
119.5 & 5009 & 0.258 \\
& 7614 & 0.193 \\
159.0 & 2060 & 0.331 \\
& 4065 & 0.271 \\
199.0 & 296 & 0.971 \\
& 980 & 0.540 \\
238.9 & 162 & 1.829 \\
& 264 & 1.139 \\
\hline
\end{tabular}

is defined by the surface that creates the original contour of the discontinuity. If the defect is located at the angle with respect to the plane " $B$ " perpendicular to the direction of nominal stress $\sigma_{\text {nom }}$, then the surface parameter " $A$ " is equal to the surface that will be created after the projection of the defect on the surface " $B$ ".

\subsection{Defect Concentration in the Area of Time Variable Stress}

The analysis of the fracture surface of the samples that failed indicates that, in a significant number of cases, the decohesion of the material does not occur rapidly. A crack increases its length until the critical length of $a_{\mathrm{kr}}$ corresponding to the emergency state occurs (Fig. 3).

This process is the result of the action of variable loads on the structural element. During the gap growth, we can distinguish three stages. The initial stage is the initiation of the gap, which arises as a result of energy accumulating near the microdefects and continues to connect to the formation of macro-cracks. The second stage is the stable gap growth until a critical length is reached, followed by the third stage of unstable growth (resulting in fatigue failure).

Thus, the total number of load change cycles until the structure is destroyed is the sum of the first two stages; however, due to the difficulty of determining the number of cycles until the initiation of the crack, it is assumed that the number of cycles during the stable gap growth is sufficient for the durability assessment.

This approach guarantees the preservation of a certain safety margin. The length of the gap from which the steady growth of the fatigue crack begins can be associated with the defect dimension in the blade casting. The propagation velocity of the fatigue gap is defined as the increase in the fracture length per one cycle (Ref 17):

$\frac{\mathrm{d} a}{\mathrm{~d} N}=f(\Delta K, R)$

where $a$-length of gap, $N$-number of cycles, $R$-cycle asymmetry coefficient, and $\Delta K$-range of variation of stress intensity coefficient expressed by formula:

$\Delta K=\Delta \sigma_{\text {nom }} \sqrt{\pi a} Y$ 

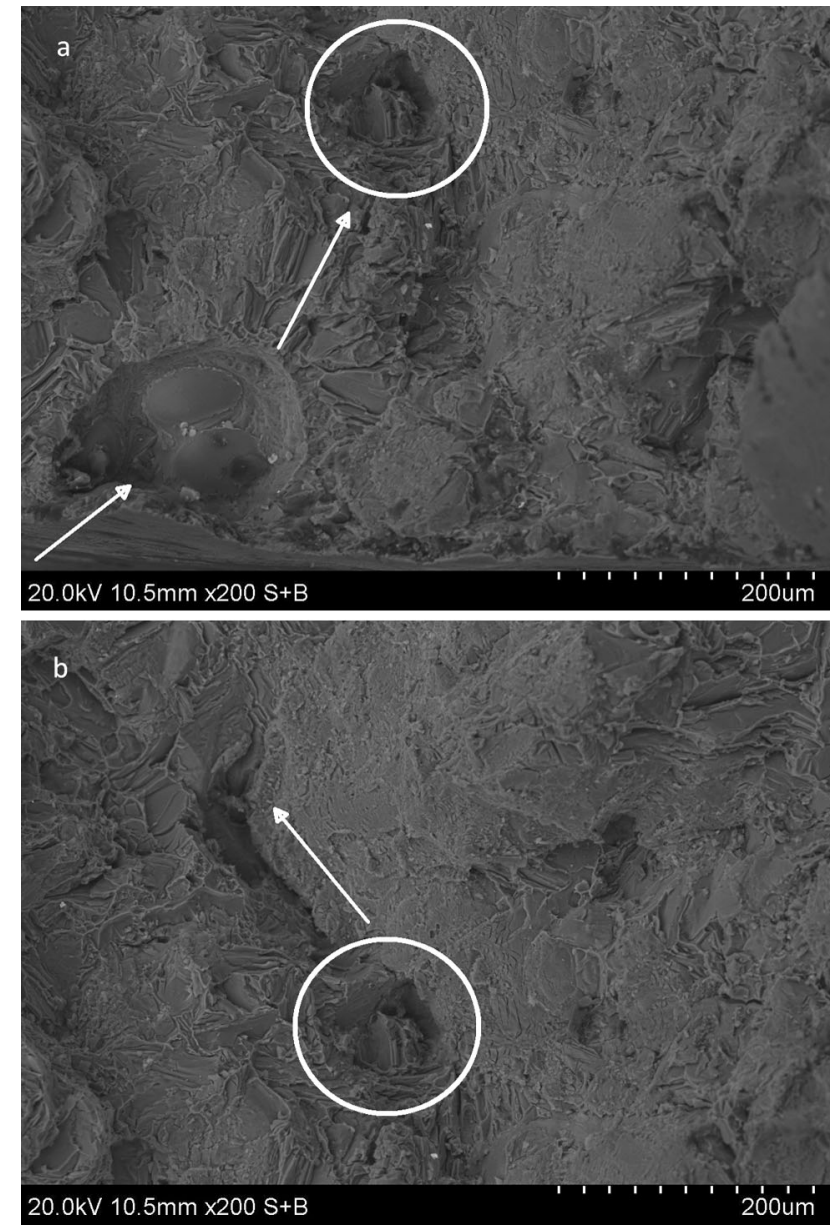

Fig. 3 Example of fatigue crack initiation of AlSi9 alloy from area of gas porosity located at edge of sample: in "a," arrow indicates porosity and direction of crack development and in " $b$ " shows continuation of crack growth. Common area was determined for both images by means of circle: stress amplitude $-\sigma \mathrm{a}=250 \mathrm{MPa}$; number of cycles to break sample $-N=865$; cycle asymmetry factor- $R=-1$

Function $\mathrm{f}$ and constants $\mathrm{m}$ and $\mathrm{C}$ are determined experimentally (so far, there is no analytical solution). For the second (the linear phase of gap growth), function $\mathrm{f}$ takes the following form:

$\log \left(\frac{\mathrm{d} l}{\mathrm{~d} N}\right)=m \log (\Delta K)+\log (C)$

Taking into account the properties of the logarithmic functions, we obtain the Paris equation:

$\frac{\mathrm{d} a}{\mathrm{~d} N}=C(\Delta K)^{m}$

To determine the number of cycles $N_{\mathrm{f}}$ after which the structure element is destroyed, Eq 7 should be transformed and integrated-additionally taking into account Formula (5) on $\Delta K$ :

$N_{\mathrm{f}}=\frac{1}{C} \int_{a_{0}}^{a_{k}} \frac{\mathrm{d} a}{(\Delta \sigma \sqrt{\pi a})^{m}}$ where $a$ is the initial length of the gap and $a$ is the final length identified by the critical length of $a^{k}$, which is determined based on the selected criterion ${ }^{\mathrm{kr}}$ of fracture mechanics. The solution of the equation requires numerical integration. The above-described method was used to determine the durability of the casting of a rotor blade made of the Al-Si alloy.

\subsection{Scattered Defects in Constant and Time Variable Stress Field}

In the case when the discontinuities of the alloy structure are small (below $1 \mathrm{~mm}$ ) and are dispersed, there are no reasons to use the equations of fracture mechanics, the defect model can then be analyzed in terms of continuous failure mechanics (assuming that the material contains uniformly distributed defects and the total volume is equal to the initial porosity). In addition, the isotropic nature of the defects measured using a scalar variable is assumed. A defect is described as a spherical void with a rising radius and a nonuniform density. The development of these voids is independent of the direction of the maximum main stress (stretching) that, in turn, is responsible for the formation of microcracks and their further propagation at the level of the microstructure. The influence of the state stress on the velocity of failure development is considered isotropic by the degree of triaxiality of stress determined by the ratio of mean stress value $\sigma_{\mathrm{m}}$ to stress intensity value $\sigma_{\text {int }}$ expressed by the $\mathrm{HMH}$ hypothesis. In addition, all components of the stress tensor and the converted value of the reduced stress $\sigma$ are updated with the development of failure directly connected only to the increase in the volume of the spherical void in this case. The above spherical model of voids in a ductile material was adopted in the description of failure evolution in the porous medium [known as the Gurson model (Ref 18), which was generalized further by Tvergaard and Needleman (Ref 19)]. The surface of plasticity is described as a function of average stress $\sigma_{\mathrm{m}}$, stress intensity $\sigma_{\text {int }}$, and the current volume density of void $f^{*}$ in this case:

$\phi\left(\sigma_{\text {int }}, \sigma_{m}, f^{*}\right)=\frac{\sigma_{\text {int }}^{2}}{\sigma_{\mathrm{pl}}^{2}}+2 q_{1} f^{*} \cosh \left(\frac{3 q_{2} \sigma_{m}}{2 \sigma_{\mathrm{pl}}}\right)-1-\left(q_{1} f^{*}\right)^{2}=0$

where $q_{1}$ and $q_{2}$ are the constants introduced by Tvergaard and Needleman (which are $q_{1}=[1-1.25]$ and $q_{2}=1$ in the case of most metal alloys). Symbol $\sigma_{\mathrm{pl}}$ indicates the current yield point of a rigid plastic material subjected to isotropic reinforcement. Function $f^{*}$, which determines the volume fraction of the voids in the GTN model, is defined as follows:

$f^{*}=f_{\mathrm{V}}+f_{\mathrm{i}}$

where $f_{\mathrm{V}}$-volume fraction of voids existing in material (porosity), $f_{\mathrm{i}}$ - volume fraction of voids initiated in deformation process.

If the proportion of the voids that initiate during the deformation growth is omitted, function $f^{*}$ will depend only on the increase in the volume of voids existing in the material and cumulative plastic deformation $\varepsilon_{\mathrm{p}}$ :

$f^{*}=\left(1-f_{\mathrm{v}}\right) \varepsilon^{\mathrm{p}}$ 


\section{Results of Numerical Calculations}

The examples presented below are the application of the calculation models discussed above and used in the analysis of the fatigue life or cracking resistance of the two analyzed alloys. In the computational models, the experimental results were used.

\subsection{Example of Defect in Time Dependency Stress Field}

The stress state in the blade was determined numerically using the FEM from the Abaqus software. The assumption was made that the aerodynamic force works as a load on the profiles of the fan blades and turbine. The boundary conditions assumed in calculation are as follows: a rotor speed of 2000 RPM and the aerodynamic coefficients according to Ref 20. It was assumed that the fatigue of the blade material occurs by increasing the maximum load from the zero value and its subsequent decrease. As a result of the calculations, the stress tensor components were obtained in a three-dimensional model of the rotor blade, which was affected by the resultant aerodynamic moment and centrifugal force. The components of the stress state of the blade casting were determined by the FEM method. In the area of the blade mounting (where porosity usually occurs), the highest value of one of the stress tensor components that has the greatest impact on the eventual crack initiation is $6 \mathrm{MPa}$. The results of the above numerical calculations were used to calculate the value of stress intensity factor $K_{\mathrm{I}}$, assuming the model of a centrally located spherical gap with a diameter of $2 a$ (where the area of Gap $A=\pi a^{2}$ ) in a static stress field using Formula 2 and analyzing the fatigue life of the blade according to $\mathrm{Eq} 7$.

Based on $\mathrm{Eq} \mathrm{2,} \mathrm{the} \mathrm{relationship} \mathrm{between} \mathrm{the} \mathrm{critical}$ dimension of the defect with a length of $2 a$ was determined by the assumed level of nominal stresses after the transformation and replacement of $K_{\mathrm{I}}$ by the experimentally determined critical value of stress intensity index $K_{\mathrm{IC}}=16.8 \mathrm{MPa} \cdot \mathrm{m}^{0.5}$ (Fig. 4). As can be seen in the graph, the crack initiation would not take place if only static loads were applied to the blade; in the case of variable loads according to Eq 7, only a defect with a diameter greater than $25 \mathrm{~mm}$ affects the destruction of the blade casting. The period to destruction is slightly less than one million cycles. Thus, on the basis of the above-mentioned procedure, it can be assumed that the porosity detected in the castings of the blade does not have a significant impact on their fatigue durability.

\subsection{Example of Concentrated Defect in Constant Stress Field}

An analysis of the fracture toughness of the samples obtained from the plate casting and determined porosity was carried out depending on the size and shape of the defect. When one of the dimensions of the defect was greater than $1.5 \mathrm{~mm}$, crack resistance coefficient $K_{\mathrm{I}}$ was determined numerically and analytically. An example of a model with defects found at the surface fracture is shown in Fig. 5. In addition, the value of the $\mathrm{K}_{\mathrm{I}}$ coefficient was determined analytically based on $\mathrm{Eq} 1,2$, and 3 .

The contour covering the defect in Fig. 5 is divided into three parts: two straight lines connected by a curve. In each of these three parts, the coordinates of the points were numerically specified in which the stress intensity factor reaches the

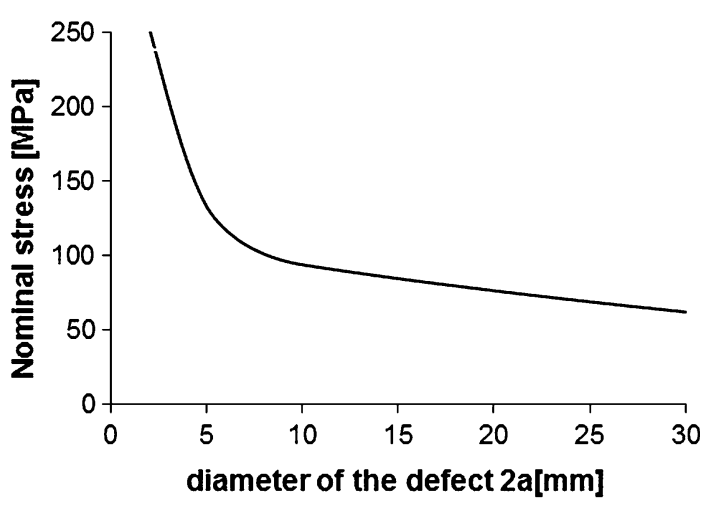

Fig. 4 Load capacity in tensile test of sample with dimension of gap $2 a$

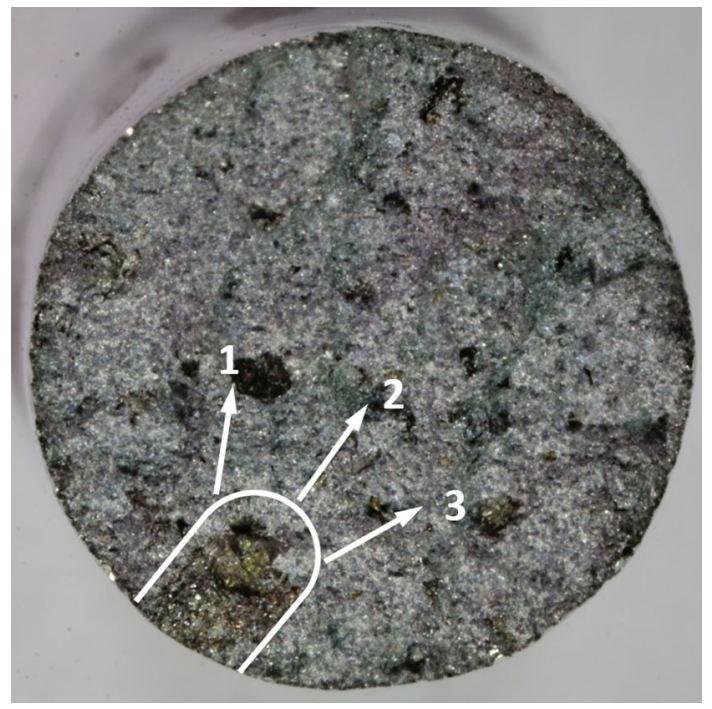

Fig. 5 Stress intensity factor determined on the basis of FEM at three points of perimeter model circuit: $K_{\mathrm{I}(\mathrm{P} 1)}=3.67 \mathrm{MPa} \cdot \mathrm{m}^{0.5}$; $K_{\mathrm{I}(\mathrm{P} 2)}=2.0 \mathrm{MPa} \cdot \mathrm{m}^{0.5} ; K_{\mathrm{I}(\mathrm{P} 3)}=3.67 \mathrm{MPa} \cdot \mathrm{m}^{0.5}$

Table 6 Values of stress intensity coefficient determined numerically- $K_{\text {I(FEM) }}$ based on Eq $1-K_{\text {I(CR) }}$ and Eq $3-K_{\text {I(SUR) }}$ as well as corresponding number of cycles for destruction $N$ and amplitude of stress $\sigma_{\mathrm{a}}$

\begin{tabular}{lrccc}
\hline $\begin{array}{l}\boldsymbol{\sigma}_{\mathbf{a}}, \\
\mathbf{M P a}\end{array}$ & $\boldsymbol{N}$ & $\begin{array}{c}\boldsymbol{K}_{\mathbf{I}(\mathbf{F E M}),} \\
\mathbf{M P a} \cdot \mathbf{m}^{\mathbf{0 . 5}}\end{array}$ & $\begin{array}{c}\boldsymbol{K}_{\mathbf{I}(\mathbf{C R})}, \\
\mathbf{M P a} \cdot \mathbf{m}^{\mathbf{0 . 5}}\end{array}$ & $\begin{array}{c}\boldsymbol{K}_{\mathbf{I}(\mathbf{S U R})}, \\
\mathbf{M P a} \cdot \mathbf{m}^{\mathbf{0 . 5}}\end{array}$ \\
\hline 79.6 & 9010 & 3.6 & 4.8 & 3.0 \\
119.5 & 1002 & 4.2 & 5.5 & 4.1 \\
159.0 & 551 & 4.5 & 7.1 & 4.2 \\
\hline
\end{tabular}

maximum value. These points fairly coincide with the place of the initiation of the crack visible at the breakthrough of the sample. The two directions of the crack propagation that led to the faction of the sample are presented by the arrows originating on the straight parts of the contour, where the value of the stress intensity factor is $3.67 \mathrm{MPa} \cdot \mathrm{m}^{0.5}$.

In Table 6 (for a comparison), the results of the numerical and analytical calculations for the determination of stress intensity factor $K_{\mathrm{I}}$ for the detected defects are presented. The 


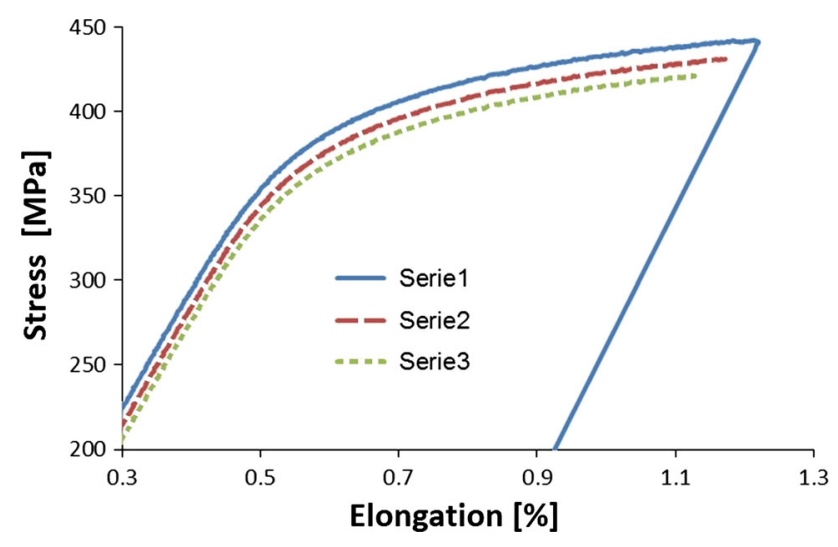

Fig. 6 Influence of porosity on curve of samples of $\mathrm{AlZn} 6 \mathrm{MgCu}$ alloy: Series 1-curve obtained experimentally as result of tensile test (porosity of less than 0.3\%); Series 2-stretching curve according to GTN model obtained by means of FEM for share of $1.5 \%$ porosity; Series 3-GTN stretch curve obtained by means of FEM for $3 \%$ porosity share

most conservative criterion is the model of a defect as a gap, in which case the values of the $K_{\mathrm{I}}$ coefficients are the largest. Performing calculations according to Eq 2 in which the parameter characterizing the size of the gap is the defect surface provides solutions similar to those obtained in the FEM method.

\subsection{Example of Scattered Defects in Constant Stress Field}

In order to illustrate the effect of the GTN equation on the change of the strength characteristics of the $\mathrm{AlZn} 6 \mathrm{MgCu}$ alloy in the FEM model, simulations of a static tensile test sample with 1.5 and $3 \%$ dispersed porosity were performed using the Abaqus program and compared to the experimental tensile test curve (Fig. 6). There are visible differences between the course of individual stretching curves because increases in porosity cause decreases in the stiffness of the material at the same level of stress.

\section{Discussion of Results}

The article presents the methodology for determining the impact of the defects detected in the casting on cracking resistance and strength. The carried-out research mainly concerns the methods of applying fracture mechanics and constitutive models of the material in the assessment of fatigue life and resistance to cracking. The method of analyzing the impact of the defect on the reduction of the strength of the cast depends on the type and size of the defect as well as the method of loading the structure. If the detected defect can be described as a void in the material (as illustrated in the example of the casting of the AlSi9 alloy rotor blade), the strength of the casting can be assessed based on the fracture mechanics methods. In this case, the value of stress intensity factor $K_{\mathrm{I}}$ can be determined and compared to its critical value $K_{\mathrm{IC}}$ (which is a material constant) using Eq 7 for cyclic variables or Eq 1 or 2 for static loads. The occurrence of scattered defects in the form of microporosity can be described by the GTN model, which takes into account the influence of microporosity on the strengthening of the material (Fig. 6). The relationship between the fatigue life and the percentage of microporosity is shown in Table 5. There is a visible relationship between the number of cycles needed for destruction and the percentage of microporosity revealed by $\mathrm{x}$-ray tomography examinations. Regardless of the value of the amplitude of the stress, a higher proportion of microporosity results in a decrease in the number of cycles.

\section{Conclusions}

The tests show the significant effect of casting defects on the fatigue properties of the tested $\mathrm{AlSi} 9$ and $\mathrm{AlZn} 6 \mathrm{MgCu}$ alloys. The obtained results present the great differences in the number of cycles to failure between samples loaded with the same stress amplitude (depending on the size and position of the defect). The number of fatigue cycles prior to the rupture of the sample was also influenced by the number of fatigue points identified on the surface of the fracture. In the case when the initiation of the crack was caused by the presence of a defect, its geometrical model was determined and calculated to determine the value of stress intensity factor $K_{\mathrm{I}}$. In the case of the samples where casting defects were identified, it was found that the stress intensity factor has a higher value when the number of fatigue cycles decreases (regardless of the stress amplitude). This relationship occurred in all of the analyzed cases regardless of the adopted calculation model despite the differences in the determined values of the stress intensity factors using analytical and numerical calculations. The adoption of a defect model in the form of a crack results in the fact that the calculated stress intensity factor has a much greater value in some cases than that calculated by means of FEM or dependence Eq 3. This difference is caused by the discrepancy between the actual shape of the defect and the model of the gap. The paper also presents the results of determining the fatigue life of a rotor blade casting based on a stress field analysis using the FEM method as well as on the basis of material tests and strength calculations based on fracture mechanics methods. On the basis of this procedure, the influence of porosity on the durability of a casting can be determined.

\section{Open Access}

This article is distributed under the terms of the Creative Commons Attribution 4.0 International License (http://creativeco mmons.org/licenses/by/4.0/), which permits unrestricted use, distribution, and reproduction in any medium, provided you give appropriate credit to the original author(s) and the source, provide a link to the Creative Commons license, and indicate if changes were made.

\section{References}

1. X.B. Cao, J. Zhao, J.H. Fan, M.H. Zhang, G.J. Shao, and Q. Hua, Influence of Casting Defects on Fatigue Behavior of A356 Aluminium Alloy, Int. J. Cast Met. Res., 2014, 27(6), p 362-368

2. K. Gal, N. Yang, M. Horstemayer, D.L. McDowell, and J. Fan, The Debonding and Fracture of Si Particles During the Fatigue of a Cast AlSi Alloy, Metall. Mater. Trans., 1999, 30A(December), p 3079-3088

3. Q.G. Wang, D. Apelian, and D.A. Lados, Fatigue Behavior of A356-T6 Aluminium Cast Alloys, Part II. Effect of Microstructural Constituents, J. Light Met., 2001, 1, p 85-97 
4. Q.G. Wang, D. Apelian, and D.A. Lados, Fatigue Behavior of A356-T6 Aluminium Cast Alloys, Part I. Effect of Casting Defects, J. Light Met., 2001, 1, p 73-84

5. Ł. Bernat, J. Hajkowski, and M. Hajkowski, Microstructure and Porosity of Aluminum Alloy Casting Whereas Mechanical Properties, Arch. Foundry, 2006, 6(22), p 41-48 (in Polish)

6. U. Fuchs, H. Lipowsky, H. Mayer, M. Papakyriacou, A. Stich, S. Tschegg, and B. Zetti, Influence of Casting Defects on the Fatigue Strength of Aluminum and Magnesium Casting Alloys, Mater. Sci. Mater. Eng., 2002, 33, p 117-127 (in German)

7. H. Kobayashi, H. Ikeda, and Y. Murakami, Extra-Long Fatigue Properties of Al-Si Eutectic Alloy by Rotating-Bending and TensionCompression Fatigue Tests, Trans. Jpn. Soc. Mech. Eng. Ser. A, 1996, 62, p 347-355

8. Y. Murakami, Analysis of Stress Intensity Factors of Mode I, II, III, for Inclined Surface Cracks of Arbitrary Shape, Eng. Fract. Mech., 1985, 22, p 101-114

9. S. Pysz, R. Żuczek, E. Czekaj, J. Piekło, and M. Maj, Lightweight, High-Strength Aluminium AlZnMgCu Alloy Castings, The 72nd World Foundry Congress, May 21-25, 2016 (Nagoya, Japan)

10. S. Pysz, E. Czekaj, R. Żuczek, M. Maj, and J. Piekło, Low Cycle Mechanical and Fatigue Properties of $\mathrm{AlZnMgCu}$ Alloy, Arch. Foundry Eng., 2016, 16(1), p 55-60

11. R. Żuczek, S. Pysz, M. Maj, and J. Piekło, Shaping the Strength of Cast Rocker Arm for Special Purpose Vehicle, Arch. Foundry Eng., 2015, 15(3), p 95-98

12. M. Maj, S. Pysz, J. Piekło, and A. Gazda, Fatigue Testing of $\mathrm{AlZnMgCu}$ Alloy Used for Parts of Suspension System, Inż. Mater. 2012, 33(6), p 635-638
13. A.P. Druschitz and J. Griffin, Advanced Cast Aluminum Alloys, 3rd International Symposium on High-Temperature Metallurgical Processing, 2009, pp. 53-60

14. Z. Kwak, S. Rzadkosz, A. Garbacz-Klempka, M. Perek-Nowak, and W. Krok, The Properties of 7xxx Series Alloys Formed by Alloying Additions, Arch. Foundry Eng., 2015, 15(2), p 59-64

15. S.T. Lim, I.S. Eun, and S.W. Nam, Control of Equilibrium Phases (M, T, S) in the Modified Aluminum Alloy 7175 for Thick Forging Applications, Mater. Trans., 2003, 44(1), p 181-187

16. J. Skrzypek, Podstawy mechaniki uszkodzeń (Basics of Defects Mechanics), Politechnika Krakowska, Kraków, 2006, p 61-67 (in Polish)

17. J. German and M. Biel-Gołaska, Podstawy $i$ zastosownie mechaniki pękania $w$ zagadnieniach inżynierskich (Basics and Application of Fracture Mechanics in Engineering Problems), Instytut Odlewnictwa, Kraków, 2004, p 131-144 (in Polish)

18. A.L. Gurson, Continuum Theory of Ductile Rupture by Void Nucleation and Growth, Part I: Yield Criteria and Flow Rules for Porous Ductile Media, J. Eng. Mater. Technol. Trans. ASME, 1977, 99(1), p 2-15

19. V. Tvergaard, Ductile Fracture by Cavity Nucleation Between Larger Voids, J. Mech. Phys. Solids, 1982, 30, p 265-286

20. H. Walden and J. Stasiak, Mechanika cieczy i gazów (Mechanics of Liquids and Gases), Państwowe Wyadawnictwo Naukowe, Warszawa, 1964, p 120-122 (in Polish)

Publisher's Note Springer Nature remains neutral with regard to jurisdictional claims in published maps and institutional affiliations. 